\title{
APLIKASI PEMESANAN LAUNDRY BERBASIS SMS GATEWAY
}

\author{
Felicia Sylviana ${ }^{\mathrm{a}, 1, *}$, Sherly Christina ${ }^{\mathrm{b}, 2}$, Sunartie $^{\mathrm{c}, 3}$ \\ ${ }^{a}$ Universitas Palangka Raya, Jl. H. Timang Palangka Raya \\ ${ }^{\mathrm{b}}$ Universitas Palangka Raya, Jl. H. Timang Palangka Raya \\ ${ }^{c}$ Universitas Palangka Raya, Jl. H. Timang Palangka Raya \\ felicia.upr@gmail.com; ${ }^{2}$ sherly.christina.upr@gmail.com; ${ }^{3}$ sunartie@mhs.it.upr.ac.id \\ * corresponding author
}

\section{ARTICLE INFO}

Keywords

Website

Waterfall method

SMS Gateway application

\section{ABSTRACT}

The development of information technology lately has entered almost all areas of our life. One of them in the field of business service provider of washing clothes or usually called the laundry. Each laundry business have its own way to improve their laundry service. In conveying information or promoting the Laundry to the community still using a manual way, and it takes very long time. So, it takes more time to get information. To able overcome these problems it is necessary to build a laundry booking application based sms gateway in Palangka Raya.

Methodology The development of this application uses the waterfall methodology, with the following stages, the first stage is the requirements analysis described using UML 2.5 (Unifer Modeling Language), the second stage is design, the third stage is coding and testing, the testing used is using blackbox, the fourth stage is implementation, the fifth stage is maintenance.

From the results of application testing, it can be concluded that this application has functioned well by providing features such as features of laundry booking based SMS Gateway and laundry profile information that contains services found in laundry

\section{Pendahuluan}

Perkembangan teknologi informasi dan komunikasi pada masa sekarang ini telah mengalami perkembangan dengan begitu cepat yang semakin canggih membuat kebutuhan akan informasi di segala bidang menjadi sangat penting. Hal ini diikuti oleh banyaknya aktivitas-aktivitas kehidupan manusia yang mencapai standar baru. Media yang paling banyak digunakan dalam memenuhi kebutuhan informasi dan komunikasi tersebut adalah komputer dan telepon seluler yang semakin disempurnakan dengan adanya internet. Internet jalur perpindahan informasi dari berbagai tempat tanpa dibatasi ruang dan waktu dalam waktu yang singkat Dimana perkembangan teknologi informasi tersebut diikuti dengan persaingan di dunia bisnis.

Secara umum SMS Gateway adalah sebuah sistem yang dipergunakan untuk memudahkan seseorang atau sebuah perusahaan mengirimkan pesan SMS yang sama dalam waktu yang bersamaan pada banyak orang. Selain itu, semakin berkembangnya fungsi SMS. SMS Gateway juga dapat dimanfaatkan untuk keperluan lain seperti melakukan polling, transaksi dengan sebuah sistem, pemantauan, dan sebagainya.seiring dengan meningkat nya sistem informasi dan komunikasi serta meningkatnya akan kebutuhan manusia, maka semakin banyak pula media atau sarana yang bermunculan. Berawal dari teknologi SMS,ada sebuah ide menarik yang banyak di adopsi dan di kembangkan, yaitu SMS gateway. SMS gateway hadir sebagai media atau sarana penyedia informasi berbasis SMS.

Usaha laundry merupakan suatu bisnis yang berkaitan dengan jasa pencucian pakaian, kegiatan pencucian pakaian ini menggunakan mesin cuci serta mesin pengering otomatis dan cairan pewangi dan pembersih khusus. Keberadaan usaha bisnis yang memberikan pelayanan jasa laundry saat ini bisa kita temukan hampir diseluruh kota khususnya kota besar, karena gaya hidup manusia saat ini yang serba praktis karena aktivitasnya yang sangat padat sehingga mereka tidak memiliki waktu luang untuk mencuci dan menyetrika pakaian maka pelayanan jasa laundry ini sangatlah berguna bagi orang yang sibuk namun menginginkan pakaiannya bersih, wangi, dan rapi. 
Dalam program yang akan dibuat ini yaitu "Aplikasi Pemesanan pada Laundry berbasis SMS Gateway", yang nantinya akan menjadi suatu program yang diharapkan bisa membantu pengguna dalam pemesanan laundry. Tentunya akan sangat membantu jika dikembangkan. Aplikasi akan dikembangkan dengan mengimplementasikan teknologi SMS Gateway yang merupakan pintu gerbang bagi penyebaran informasi dengan menggunakan Short Message Service (SMS), yang mana SMS adalah salah satu fitur dari Global System for Mobile Communication (GSM) dan penggunanya yang sangat banyak. SMS Gateway adalah merupakan komunikasi dua arah, mengirim dan menerima, dengan tarif normal yang telah ditentukan oleh operator seluler [1]. Short Message Service (SMS) Gateway adalah sebuah system yang mampu menerima kode SMS dengan jumlah tertentu, mengolah informasi yang terkandung dalam pesan SMS dan melakukan transaksi yang dibutuhkan [2].

Penggunaan aplikasi yang berbasis website dan SMS Gateway sebagai salah satu cara promosi dalam penyebaran informasi dapat menjadikan proses promosi bisa dilakukan lebih mudah, efisien dan tetap memungkinkan interaksi antara pelanggan dan laundry dalam hal melakukan pemesanan.

\section{Metodologi Penelitian}

\subsection{Perancangan Arsitektur Sistem (SMS Gateway)}

SMS Gateway berada diantara dua Short Message Service Center (SMSC) yang berfungsi untuk meneruskan pesan SMS dari SMSC sumber ke SMSC tujuan. Dengan berkembangnya teknologi, SMS Gateway tidak lagi berfungsi untuk menghubungkan SMSC satu dengan lain tetapi saat ini dapat juga diartikan sebagai penghubung komunikasi antara perangkat komunikasi, berupa telepon seluler, modem Global System For Mobile (GSM), ataupun modem Code Division Multiple Access (CDMA) dengan perangkat komputer, sehingga mempermudah aktivitas dan pengelolaan SMS [4].

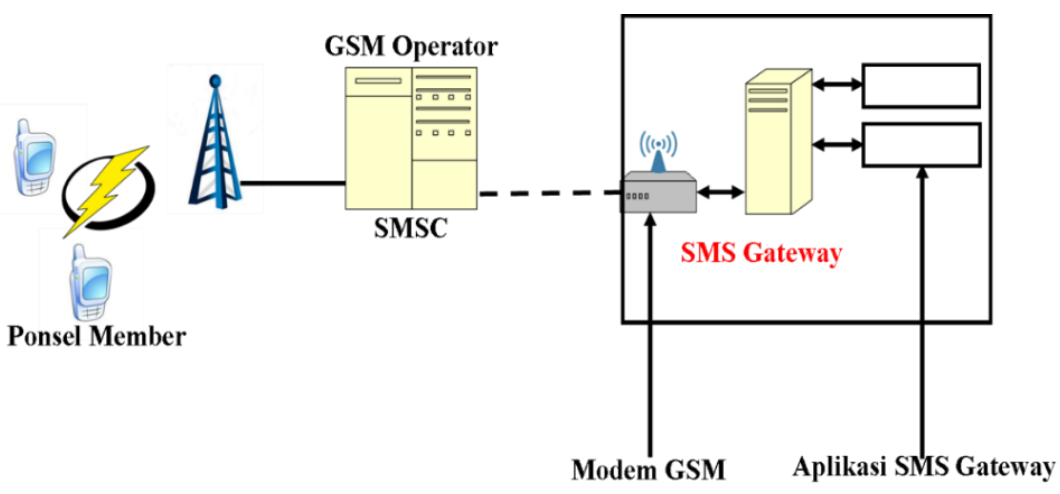

Gambar 1.Ilustrasi SMS Gateway

\subsection{Metodologi Pengembangan Aplikasi}

Metodologi yang digunakan metode pengembangan waterfall.

Adapun pengembangan waterfall meliputi beberapa bagian atau fase - fase yang meliputi :

1. Analisis

Pada bagian ini berisi rancangan dasar situs yang akan dibuat sesuai dengan sasaran awal situs. Terlebih dulu membuat analisis dari sistem yang sedang berjalan pada Laundry. Kemudian dari sistem lama dibuat rekomendasi sistem baru. Pada tahap ini desain perancangannya dengan menggunakan UML 2.5 (Unifer Modeling Language) yang digunakan pada UML 2.5 yaitu, flowchart sistem bisnis proses lama dan flowchart sistem bisnis proses baru, use case diagram, activity diagram, class diagram.

2. Desain

Pada tahapan ini akan dibuat berbagai desain, yaitu :

- Desain navigasi 
- Desain interface storyboard

\section{Coding Dan Testing}

Desain yang telah dibuat akan diubah ke dalam bentuk yang dapat dimengerti oleh sistem komputer, yaitu ke dalam bahasa pemrograman melalui proses coding, menggunakan PHP dan MYSQL. Tahap ini merupakan implementasi dari tahap desain yang secara teknis akan dikerjakan oleh programmer. Dalam melakukan proses coding juga dilakukan proses testing untuk menguji dan melihat kesalahan yang ada pada program maupun fungsi dari sistem , testing yang digunakan yaitu menggunakan blackbox.

4. Implementasi

Setelah melewati tahapan coding dan testing maka produk yang telah dibuat akan diimplementasikan untuk menampilkan hasil.

5. Pemeliharaan

Pemeliharaan sangat diperlukan, termasuk di dalamnya adalah pengembangan, karena website yang dibuat tidak selamanya hanya seperti itu. Ketika dijalankan mungkin saja masih ada kesalahan kecil yang tidak ditemukan sebelumnya, atau ada penambahan fitur-fitur yang belum ada pada website tersebut.

Adapun pada Gambar 2. merupakan diagram alur metodologi waterfall.

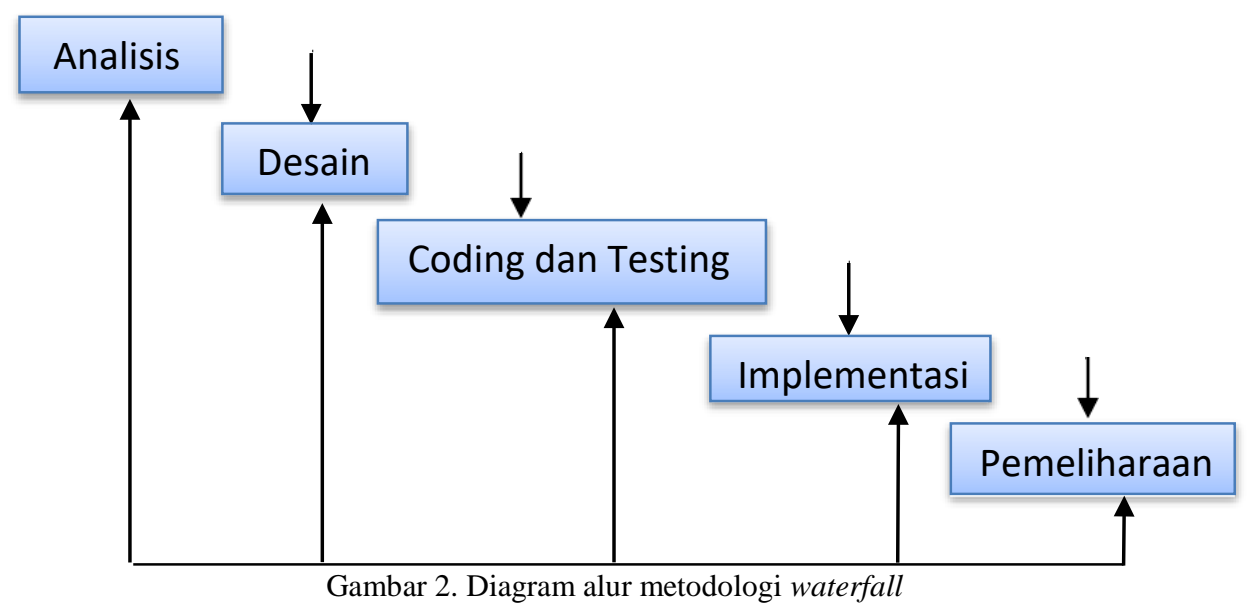

\section{Hasil dan Pembahasan}

Setelah dilakukan analisis dari sistem yang sedang berjalan pada laundry, kemudian dari sistem lama dibuat rekomendasi sistem baru sehingga akhirnya diketetahui bahwa terdapat 2 (dua) aktor yang akan menggunakan aplikasi laundry yaitu seperti yang terlihat pada tabel 1.berikut ini:

Tabel 1. Definisi Aktor pada Website

\begin{tabular}{|c|l|l|}
\hline $\begin{array}{c}\text { No } \\
\cdot\end{array}$ & \multicolumn{1}{|c|}{ Aktor } & \multicolumn{1}{c|}{ Deskripsi } \\
\hline 1. & Admin & $\begin{array}{l}\text { Orang yang berhak mengakses dan } \\
\text { mengelola system secara menyeluruh. }\end{array}$ \\
\hline 2. & Pengunjung & $\begin{array}{l}\text { Memiliki hak akses terbatas seperti melihat fitur } \\
\text { Beranda,fitur Profil,fitur } \\
\text { informasi Layanan dan fitur Galeri. }\end{array}$ \\
\hline
\end{tabular}

Berikut ini adalah beberapa tampilan antarmuka aplikasi laundry :

Gambar 3.menunjukan implementasi fitur Layanan untuk menampilkandaftar layanan pada pengunjung aplikasi laundry yang berbasis website. 

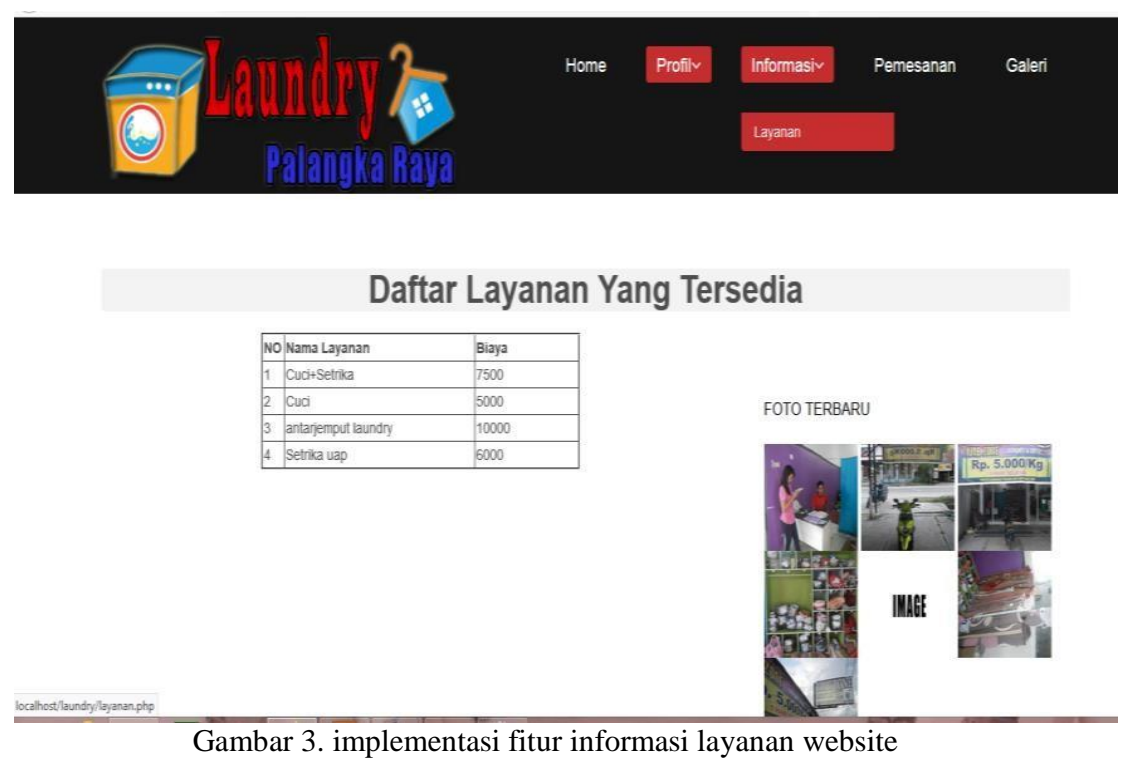

Gambar 4. Menampilkan daftar pemesanan layanan antar jemput untuk halaman pengunjung pada website.

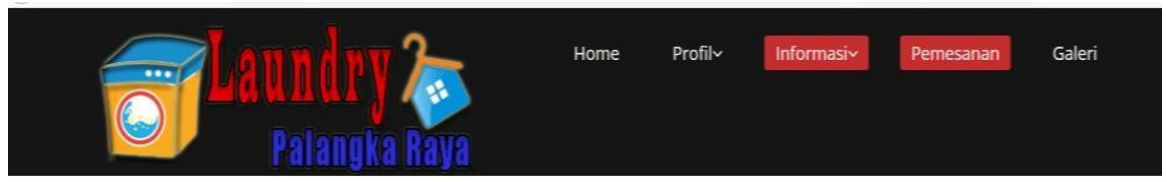

\section{DAFTAR LAYANAN ANTAR JEMPUT}

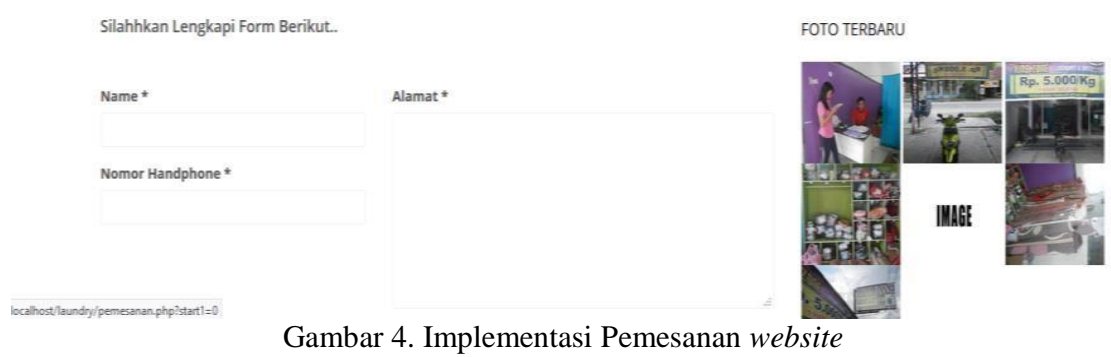

Gambar 5. Menunjukan implementasi tampilan Admin kelola pesan Siaran pada SMS Gateway. 


\section{JURNAL TEKNOLOGI INFORMASI}

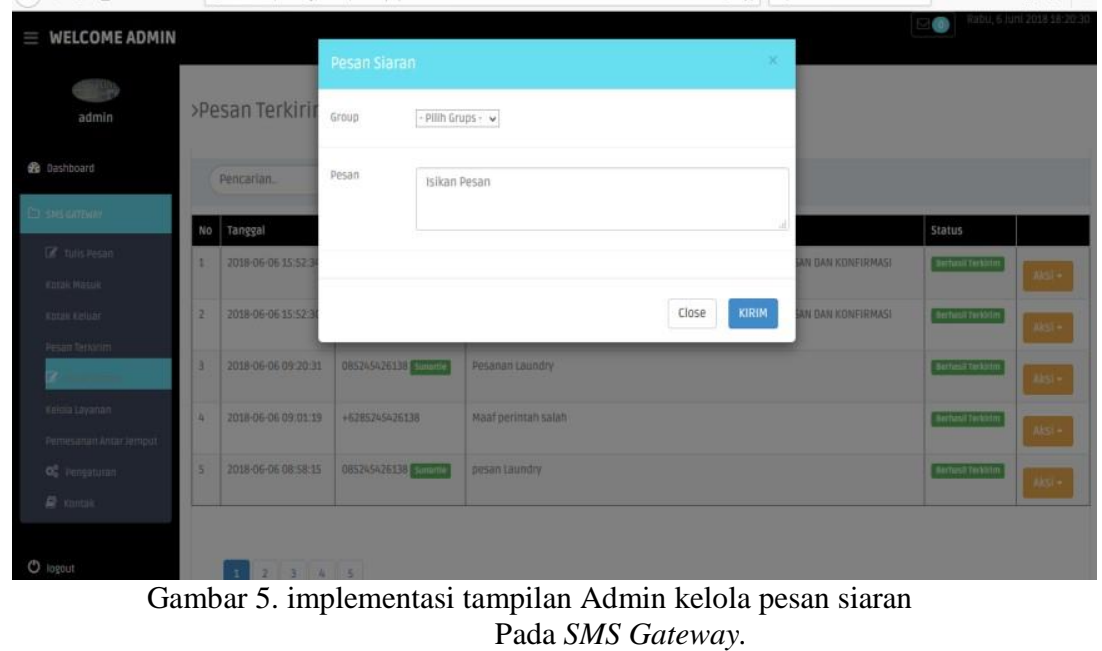

Gambar 6. Menunjukan implementasi tampilan Admin kelola auto replay pada SMS Gateway.

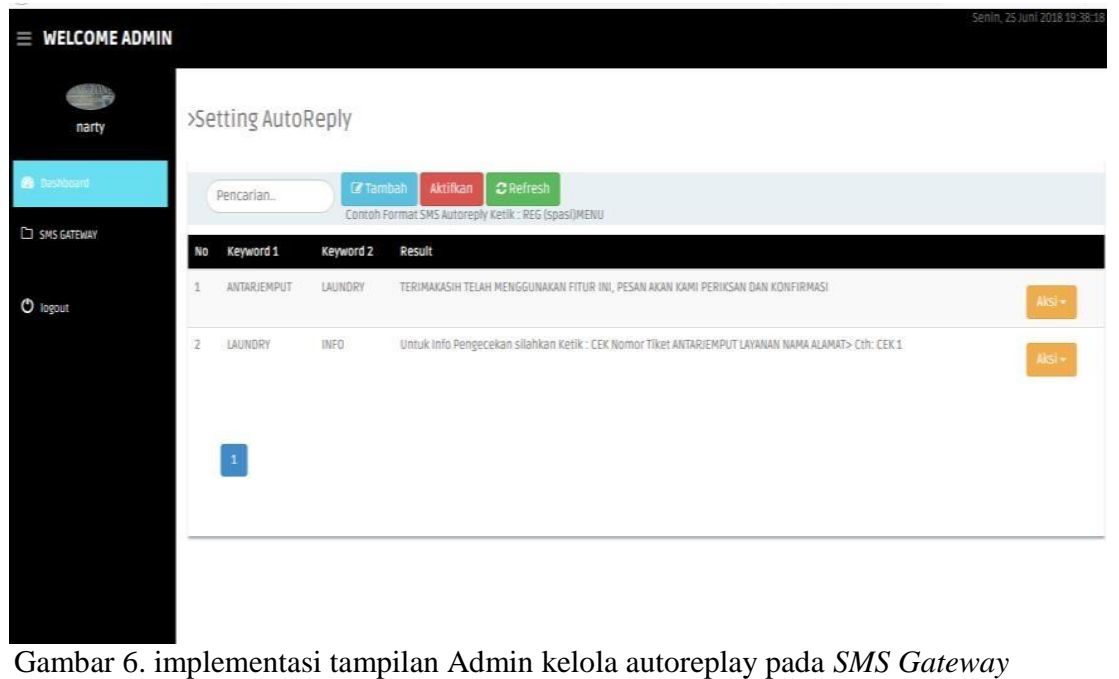

\section{Kesimpulan}

Untuk merancang dan membangun sistem SMS Gateway pada laundry dilakukan dengan tahapan sebagai berikut :

- Pengumpulan data, dengan teknik observasi dan study literatur.

- Perancangan arsitektur sistem

- Pembuatan aplikasi

Pembuatan aplikasi dibuat dengan menggunakan metode pengembangan waterfall dengan tahapan analisi, desain, testing dan coding, implementasi dan Pemeliharaan.rancangan design aplikasi menggunakan Unifed Modeling Language (UML), meliputi Use Case Diagram, class Diagram, Activity Diagram dan navigation. Software tools yang digunakan dalam pembuatan aplikasi yaitu : Microsoft Visio 2010,MySQL, Php, Xampserver.

Dari tahapan diatas maka dihasilkan aplikasi pemesanan laundry yang berbasis sms gateway, aplikasi ini bertujuan untuk menyediakan pemesanan antar jemput laundry dan fasilitas dalam pemesanan laundry.

Adapun saran yang disampaikan sebagai pengembangan aplikasi kedepannya adalah agar ditambahkan fitur laporan keuangan untuk mengetahui rincian keuangan pengeluaran dan pendapatan pada laundry. 


\section{DaftarPustaka}

[1] AgusSaputra . 2011. Membangun Aplikasi SMS Dengan PHP dan MySQL. Jakarta: Elex Media Komputindo.

[2] Dewanto RA, Aradea. 2007. Aplikasi SMS Gateway dengan Koreksi Kesalahan Menggunakan Fuzzy String Matching.

[3] Ihsan (2010), Pengembangan Sistem Informasi Laundry Pada PerusahaanRefresh Laundry Dengan Menggunakan Bahasa Pemrograman Java, UPI,Padang.

[4] M. Firdaus, and y. yuniarto, "Simulasi Sistem Peringatan Dini Ketinggian Air Sungai Dengan Menggunakan Alarm Dan Sms Gateway Berbasis At-Mega 16," Gema Teknologi, vol. 19, no. 3, pp. 7-13, Oct. 2017. https://doi.org/10.14710/gt.v19i3.21879

[5] Martono Teguh Kurniawan Pembuatan Aplikasi Antar-Jemput Laundry Berbasis Web Service pada Platform Android[PDF] Program Studi Sistem Komputer Fakultas Teknik Universitas Diponegoro Jalan Prof. Sudharto, Tembalang, Semarang, Indonesia yenireksotinoyo@gmail.com Di akses januari 2016.

[6] Nore Nicolas viktor, Perancangan sistem informasi penjualan dan pemesanan produk berbasis web (study kasus di CV.Richness Development Bandung) januari 2013.

[7] Ramadhika.A , file:///G://SMS Gateway Menggunakan Gammu Dan MySQ Universitas Surabaya (UBAYA).html Di akses 29 februari 2012.

[8] Suprayogi, D.A., and W.F. Mahmudy, "Penerapan Algoritma Genetika Traveling Salesman Problem with Time Window : Studi Kasus Rute Antar Jemput Laundry,” Buana Inform, vol. 6, pp. 121-130, 2014. 